\title{
Prediction modeling of power and torque in end-milling
}

\author{
K. Kadirgama ${ }^{1}$, M. M. Noor ${ }^{1}$, M. M. Rahman ${ }^{1}$, M. S. M. Sani ${ }^{1}$, \\ M. R. M. Rejab ${ }^{1}$, R. A. Bakar ${ }^{1}$ \& K. A. Abou-El-Hossein ${ }^{2}$ \\ ${ }^{1}$ University Malaysia Pahang, Malaysia \\ ${ }^{2}$ Nelson Mandela Metropolitan University, South Africa
}

\begin{abstract}
This paper presents the development of mathematical models for torque and power in milling 618 stainless steel using coated carbide cutting tools. The response surface method was used to predict the effect of power and torque in the end-milling. From the model, the relationship between the manufacturing process factors, including the cutting speed, feed rate, axial depth and radial depth with the responses such as torque and power, can be developed. Beside the relationship, the effect of the factors can be investigated from the equation developed. It can be seen that the torque increases with a decrease of cutting speed with an increase of the feed rate, axial depth and radial depth. The acquired results also show that the power increase with an increase in cutting speed, feed rate, axial depth and radial depth. It can be found that the second order is more accurate based on the variance analysis and the predicted value is closely matched with the experimental result. Third- and fourth-order models are generated for both responses to investigate the 3- and 4-way interaction between the factors. The third- and fourth-order models show that 3- and 4-way interaction was found to be less significant for the variables.
\end{abstract}

Keywords: torque, power, end-milling, response surface method.

\section{Introduction}

In this work, experimental results were used for modeling using response surface roughness methodology (RSM) [1]. The RSM is practical, economical and relatively easy to use and it has been used by many researchers for modeling 
machining processes [2-4]. Mead and Pike [5] and Hicks [6] reviewed the earliest work on response surface methodology. RSM is a combination of experimental and regression analysis and statistical inferences. The concept of a response surface involves a dependent variable y called the response variable and several independent variables $x_{1}, x_{2} \ldots x_{k}$ [7]. The main aim of the paper is to investigate the effect of variables towards the responses and investigate the 3 and 4-way interaction between the factors.

\section{Torque and power model}

The proposed relationship between the responses (torque and power) and machining independent variables can be represented by the following:

$$
\begin{aligned}
& \tau=C\left(V^{m} F^{n} A_{x}^{y} A_{r}^{z}\right) \varepsilon^{\prime} \\
& P=C\left(V^{m} F^{n} A_{x}^{y} A_{r}^{z}\right) \varepsilon
\end{aligned}
$$

where $\tau$ is the torque in Nm, $P$ is the power in watts, $V, F, A_{x}$, and $A_{r}$ are the cutting speed $(\mathrm{m} / \mathrm{s})$, feed rate $(\mathrm{mm} / \mathrm{rev})$, axial depth $(\mathrm{mm})$ and radial depth $(\mathrm{mm})$. $C, m, n, y$ and $z$ are the constants. Equations (1) and (2) can be written in the following logarithmic form:

$$
\begin{aligned}
& \ln \tau=\ln C+m \ln V+n \ln F+y \ln A_{x}+z \ln A_{r}+\ln \varepsilon^{\prime} \\
& \ln P=\ln C+m \ln V+n \ln F+y \ln A_{x}+z \ln A_{r}+\ln \varepsilon^{\prime}
\end{aligned}
$$

Equations (3) and (4) can be written as a linear form:

$$
\begin{gathered}
\tau=\beta_{0} x_{0}+\beta_{1} x_{1}+\beta_{2} x_{2}+\beta_{3} x_{3}+\beta_{4} x_{4}+\varepsilon \\
P=\beta_{0} x_{0}+\beta_{1} x_{1}+\beta_{2} x_{2}+\beta_{3} x_{3}+\beta_{4} x_{4}+\varepsilon
\end{gathered}
$$

where $\tau$ is the torque in $\mathrm{Nm}, P$ is the power in watts, $x_{0}=1$ (dummy variables), $x_{1}=\ln V, x_{2}=\ln F, x_{3}=\ln A_{x}, x_{4}=\ln A_{r}$ and $\varepsilon=\ln \varepsilon$, where $\varepsilon$ is assumed to be a normally-distributed uncorrelated random error with zero mean and constant variance, $\beta_{0}=\ln C$ and $\beta_{1}, \beta_{2}, \beta_{3}$, and $\beta_{4}$ are the model parameters. The second model can be expressed as:

$$
\begin{aligned}
& y^{\prime \prime}=\beta_{0} x_{0}+\beta_{1 x_{1}}+\beta_{2 x_{2}}+\beta_{3} x_{3}+\beta_{4} x_{4}+\beta_{11} x^{2}{ }_{1}+\beta_{22} x^{2}{ }_{2}+\beta_{33} x^{2}{ }_{3}+\beta_{44} x^{2}{ }_{4}+\beta_{11} x_{1} x_{2}+ \\
& \beta_{12} x_{1} x_{3}+\beta_{13} x_{1} x_{4}+\beta_{14} x_{2} x_{3}+\beta_{15} x_{3} x_{4}
\end{aligned}
$$

The values of $\beta_{1}, \beta_{2}, \beta_{3}$, and $\beta_{4}$ are to be estimated by the method of least squares. The basic formula is:

$$
\beta=\left(x^{T} x\right)^{-1} x^{T} y
$$


where $x^{T}$ is the transpose of the matrix $x$ and $\left(x^{T} x\right)^{-1}$ is the inverse of the matrix $\left(x^{T} x\right)$ and $y$ is the value from experiment. The details of the solution by this matrix approach are explained in [1]. The parameters have been estimated by the method of least-squares using a Matlab computer package.

\subsection{Experimental design}

To develop the first-order, a design consisting of 27 experiments was conducted. Box-Behnken Design is normally used when performing non-sequential experiments, which are, performing the experiment only once. These designs allow efficient estimation of the first- and second-order coefficients. Because Box-Behnken Design has fewer design points, it is less expensive to run than central composite designs with the same number of factors. Box-Behnken Design does not have axial points, thus one can be sure that all design points fall within the safe operating parameters. Box-Behnken Design also ensures that all factors are never set at their high levels simultaneously [8-10]. Preliminary tests were carried out to find the suitable cutting speed, federate, axial depth and radial depth as shown in table 1.

\subsubsection{Experimental details}

The 618 stainless steel workpieces were provided in fully annealed condition in sizes of $65 \times 170 \mathrm{~mm}$. The tools used in this study are carbide inserts PVD coated with one layer of TiN. The inserts are manufactured by Kennametal with ISO designation of $\mathrm{KC} 735 \mathrm{M}$. They are specially developed for milling applications where stainless steel is the major machined material. The end-milling tests were conducted on an Okuma CNC machining center MX-45VA. Every one passes (one pass is equal to $85 \mathrm{~mm}$ ), the cutting test was stopped. The same experiment has been repeated three times to get a more accurate result.

\section{Results and discussion}

\subsection{First-order model for the torque and power model}

The machining power is the product of cutting speed, $v$ and the cutting force, $F_{c}$. Thus the equation for the power is:

$$
P=F_{c} v
$$

Table 1: $\quad$ Levels of independent variables.

\begin{tabular}{|c|c|c|c|}
\hline Factors $\backslash$ Coding of Levels & -1 & 0 & 1 \\
\hline Speed, $V_{c}(\mathrm{~m} / \mathrm{s})$ & 100 & 140 & 180 \\
\hline Feed, $f(\mathrm{~mm} / \mathrm{rev})$ & 0.1 & 0.2 & 0.3 \\
\hline Axial depth of cut, $a_{a},(\mathrm{~mm})$ & 1 & 1.5 & 2 \\
\hline Radial depth of cut, $a_{r},(\mathrm{~mm})$ & 2 & 3.5 & 5 \\
\hline
\end{tabular}


where $P$ is the power in watts, $v$ is the cutting speed in $\mathrm{m} / \mathrm{min}$ and $F_{c}$ is the cutting force from the experiment in N. From the equation (9), the power can be calculated. The first order model from Matlab for power and torque are:

$$
\begin{gathered}
P^{\prime}=6.1993+0.1633 x_{1}+0.3025 x_{2}+0.26 x_{3}+0.2592 x_{4} \\
T^{\prime}=2.6215-0.1308 x_{1}+0.2292 x_{2}+0.1408 x_{3}+0.2142 x_{4}
\end{gathered}
$$

The predicted result from the first order model for power and torque are shown in figure 1(a) and 1(b). Tables 2 and 3 show the $95 \%$ confidence interval for the experiments and analysis of variance. For the linear model, the p-values for lack of fit are 0.196 and 0.123 . Therefore, the model is adequate. The transforming equations for each of the independent variables are:

$$
\begin{gathered}
x_{1}=\frac{\ln (V)-\ln (v) \text { centre }}{\ln (v) \text { high }-\ln (v) \text { centre }} x_{2}=\frac{\ln (F)-\ln (f) \text { centre }}{\ln (f) \text { high }-\ln (f) \text { centre }} \\
x_{3}=\frac{\ln \left(A_{x}\right)-\ln \left(a_{x}\right) \text { centre }}{\ln \left(a_{x}\right) \text { high }-\ln \left(a_{x}\right) \text { centre }} x_{4}=\frac{\ln \left(A_{r}\right)-\ln \left(a_{r}\right) \text { centre }}{\ln \left(a_{r}\right) \text { high }-\ln \left(a_{r}\right) \text { centre }}
\end{gathered}
$$

Table 2: $\quad$ ANOVA for power.

\begin{tabular}{|c|c|c|c|}
\hline Source & $\begin{array}{c}\text { Degree of } \\
\text { freedom }\end{array}$ & F ratio & P-value \\
\hline Regression & 4 & 186.37 & 0 \\
\hline Linear & 4 & 186.37 & 0 \\
\hline Residual Error & 22 & & \\
\hline Lack-of-Fit & 20 & 5.1033 & 0.196 \\
\hline Total & 26 & & \\
\hline
\end{tabular}

Table 3: $\quad$ ANOVA for torque.

\begin{tabular}{|c|c|c|c|}
\hline Source & $\begin{array}{c}\text { Degree of } \\
\text { freedom }\end{array}$ & F ratio & P-value \\
\hline Regression & 4 & 39.69 & 0 \\
\hline Linear & 4 & 39.69 & 0 \\
\hline Residual Error & 22 & & \\
\hline Lack-of-Fit & 20 & 7.56 & 0.123 \\
\hline Total & 26 & & \\
\hline
\end{tabular}




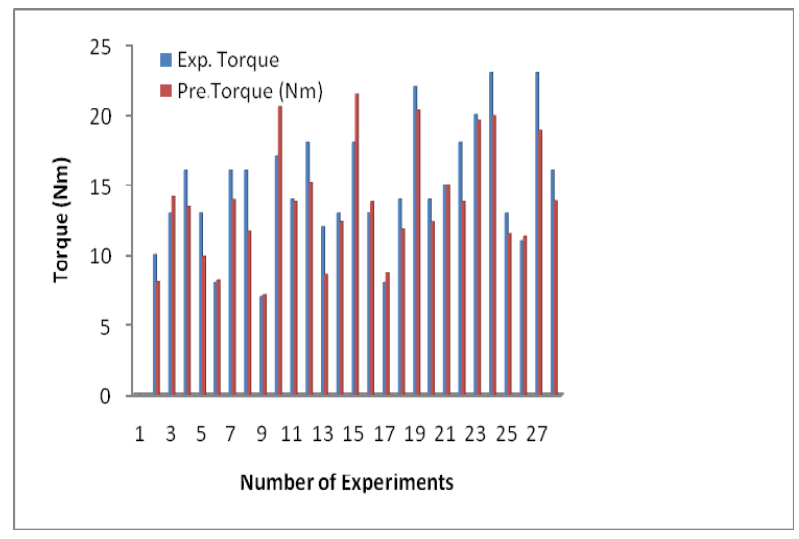

(a)

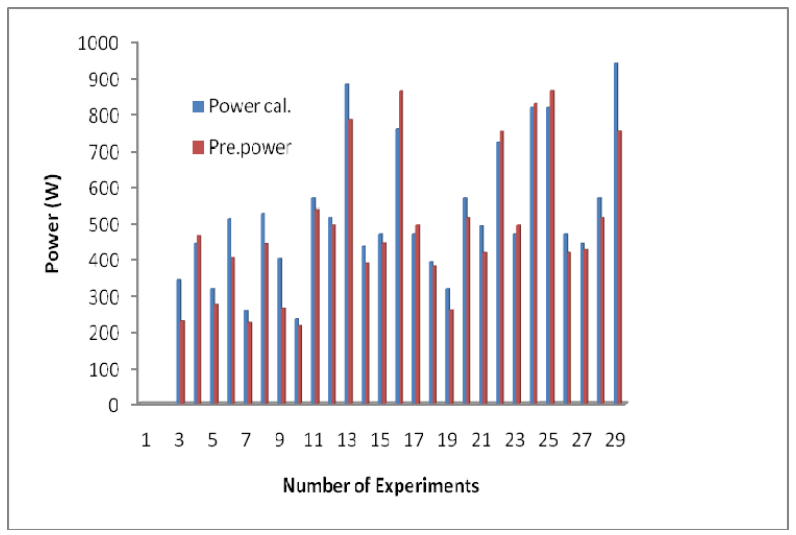

(b)

Figure 1: Comparison between predicted value and experimental for: (a) power, (b) torque.

Equation (9) describing the torque and power model can be transformed using Equation (12) into the following form:

$$
\begin{gathered}
T^{\prime}=315.23\left(V^{0.5204} F^{0.796719} A_{x}^{0.489432} A_{r}^{0.60055}\right) \\
P^{\prime}=3.7065\left(V^{0.6498} F^{1.0515} A_{x}^{0.9037} A_{r}^{0.7267}\right)
\end{gathered}
$$

This result shows that feed rate has the most significant effect on the torque, follow by axial depth, radial depth and cutting speed. The equation shows that the torque increase with reducing the cutting speeds. Equation (13) is utilized to develop torque contour at the selected cutting speed, and feed rate. Figure 2 shows the torque contour with selected cutting speed and feed rate. These contours help to predict the torque at any zone of experimental zone. From the contour, the torque reaches the highest value when the value of cutting speed at its lower value, feed rate, axial depth and radial depth are at their maximum 


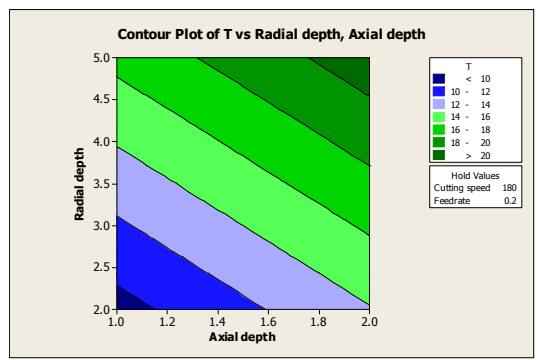

Figure 2: Torque contours in the axial depth-radial depth plane for cutting speed $180 \mathrm{~m} / \mathrm{s}$ and feed rate $0.2 \mathrm{~mm} / \mathrm{rev}$.

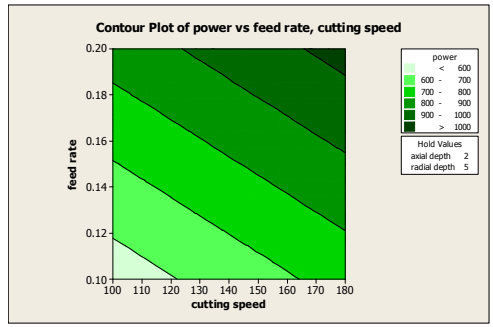

Figure 3: Power surface plot in the cutting speed-feed rate plane for axial depth $2 \mathrm{~mm}$ and radial depth $5 \mathrm{~mm}$.

value. From this contour plot, the safety zone of torque can be selected for any experiment. The equation shows that the power increases with increasing feed rate, axial depth and radial depth. Equation (14) is utilized to develop power surface plot at the selected axial depth, radial depth. Figure 3 shows the power plot with selected axial and radial depth.

\subsection{Second-order and third-order model for torque and power}

The second-order model was postulated in obtaining the relationship between the responses and the machine independent variables. The model equations are:

$$
\begin{aligned}
& P^{\prime \prime}=2.05074-0.031 x_{1}+47.37 x_{2}+2.97 x_{3}+1.60 x_{4}+0.00029 x^{2}{ }_{1}-50.17 x^{2}{ }_{2}-0.78 x^{2}{ }_{3} \\
& -0.14 x^{2}{ }_{4}-0.29 x_{1} x_{2}-0.018 x_{1} x_{3}-0.0094 x_{1} x_{4}+24.3 x_{2} x_{3}+12.8 x_{2} x_{4}+0.80 x_{3} x_{4} \\
& T^{\prime \prime}=-2080-17.22 x_{1}-3099.72 x_{2}-945.20 x_{3}-113.22 x_{4}+0.036 x_{1}{ }_{1}-3315.17 x^{2}{ }_{2}+146.30 x^{2}{ }_{3} \\
& +2.55 x^{2}{ }_{4}+30 x_{1} x_{2}+2.25 x_{1} x_{3}+0.49 x_{1} x_{4}+1633.40 x_{2} x_{3}+116.63 x_{2} x_{4}+63.52 x_{3} x_{4}
\end{aligned}
$$

The third-order model obtained to investigate the 3-way interaction between the variables. The third-order model as shown below: 


$$
\begin{aligned}
& y^{\prime \prime \prime}=c+\beta_{1} x_{1}+\beta_{2} x_{2}+\beta_{3} x_{3}+\beta_{4} x_{4}+\beta_{5} x_{1}^{2} \beta 6 x^{2}{ }_{2}+\beta_{7} x^{2}{ }_{3}+\beta_{8} x^{2}{ }_{4}+\beta_{9} x_{1}^{3}+\beta_{10} x^{3}+\beta_{11} x^{3}{ }_{3} \\
& \beta_{12} x_{4}^{3}+\beta_{13} x_{1} x_{2}+\beta_{14} x_{1} x_{3}+\beta_{15} x_{1} x_{4}+\beta_{16} x_{2} x_{3}+\beta_{17} x_{2} x_{4}+\beta_{18} x_{3} x_{4}+\beta_{19} x_{1} x_{2} x_{3}+\beta_{20} x_{1} x_{2} x_{4}+ \\
& \beta_{21} x_{1} x_{3} x_{4}+\beta_{22} x_{2} x_{3} x_{4}
\end{aligned}
$$

From this model, the most important points are the main effect, 2-way interaction and 3-way interaction. So the third order model can be reduced as below:

$$
\begin{aligned}
& y^{\prime \prime \prime}=c+\beta_{1} x_{1}+\beta_{2} x_{2}+\beta_{3} x_{3}+\beta_{4} x_{4}+\beta_{13} x_{1} x_{2}+\beta_{14} x_{1} x_{3}+\beta_{15} x_{1} x_{4}+\beta_{16} x_{2} x_{3}+\beta_{17} x_{2} x_{4}+\beta_{18} x_{3} x_{4} \\
& +\beta_{19} x_{1} x_{2} x_{3}+\beta_{20} x_{1} x_{2} x_{4}+\beta_{21} x_{1} x_{3} x_{4}+\beta_{22} x_{2} x_{3} x_{4}
\end{aligned}
$$

These model parameters can be solved using least squares method. $\beta$ are the model parameters, $x_{1}=$ cutting speed, $x_{2}=$ feedrate, $x_{3}=$ axial depth and $x_{4}=$ radial depth. The third order model for torque and power are:

$$
\begin{aligned}
& T^{\prime \prime \prime}=-176.95+1.3922 x_{1}+1103.97 x_{2}-7.6632 x_{3}+56.7540 x_{4}-7.8022 x_{1} x_{2}-0.05 x_{1} x_{3} \\
& -0.4237 x_{1} x_{4}+50 x_{2} x_{3}-353.753 x_{2} x_{4}+3.4863 x_{3} x_{4}+2.4792 x_{1} x_{2} x_{3} \\
& P^{\prime \prime}=-9728+70 x_{1}+1024 x_{2}-2048 x_{3}+409 x_{4}-19 x_{1} x_{3}-31 x_{1} x_{4}+23.552 x_{2} x_{3}-1049 x_{2} x_{4} \\
& -1408 x_{3} x_{4}-168 x_{1} x_{2} x_{3}+82 x_{1} x_{2} x_{4}+14 x_{1} x_{3} x_{4}+512 x_{2} x_{3} x_{4}
\end{aligned}
$$

The variance analysis for the torque and power carried out to determine the model is adequate and significant of 3-way interaction for both models are shown in tables 4 and 5. From the variance analysis both models are not significant to the 3 -way interaction since the $\mathrm{p}$ value $>0.05$. The third-order model is adequate for torque and power since the p-value for lack of fit for torque is 0.818 and for power is 0.135 . F-static for torque and power are 0.52 and 6.77 .

Table 4: $\quad$ Variance analysis for third-order torque model.

\begin{tabular}{|c|c|c|c|}
\hline Source & Degree of freedom & F ratio & P-value \\
\hline Main effect & 4 & 11.80 & 0 \\
\hline 2-Way Interactions & 6 & 1.85 & 0.156 \\
\hline 3-Way Interactions & 1 & 3.96 & 0.065 \\
\hline Residual error & 15 & & \\
\hline Lack of Fit & 12 & 0.52 & 0.818 \\
\hline Total & 26 & & \\
\hline
\end{tabular}


Table 5: $\quad$ Variance analysis for third-order power model.

\begin{tabular}{|c|c|c|c|}
\hline Source & Degree of freedom & F ratio & P-value \\
\hline Main effect & 4 & 35.60 & 0 \\
\hline 2-Way Interactions & 6 & 1.55 & 0.244 \\
\hline 3-Way Interactions & 4 & 1.10 & 0.402 \\
\hline Residual error & 12 & & \\
\hline Lack of Fit & 10 & 6.77 & 0.135 \\
\hline Total & 26 & & \\
\hline
\end{tabular}

\subsection{Fourth-order model for torque and power}

The fourth-order model obtained to investigate the 4-way interaction between the variables. The fourth-order model as shown below:

$$
\begin{aligned}
& y^{\prime \prime \prime}=c+\beta_{1} x_{1}+\beta_{2} x_{2}+\beta_{3} x_{3}+\beta_{4} x_{4}+\beta_{5} x_{1}^{2} \beta_{6} x_{2}^{2}+\beta_{7} x^{2}{ }_{3}+\beta_{8} x^{2}{ }_{4}+\beta_{9} x^{3}+\beta_{10} x^{3}{ }_{2}+\beta_{11} x^{3}{ }_{3} \\
& +\beta_{12} x^{3}{ }_{4}+\beta_{13} x_{1}{ }_{1}+\beta_{14} x^{4}{ }_{2}+\beta_{15} x^{4}{ }_{3}+\beta_{16} x^{4}{ }_{4}+\beta_{17} x_{1} x_{2}+\beta_{18} x_{1} x_{3}+\beta_{19} x_{1} x_{4}+\beta_{20} x_{2} x_{3}+\beta_{21} x_{2} x_{4} \\
& +\beta_{22} x_{3} x_{4}+\beta_{23} x_{1} x_{2} x_{3}+\beta_{24} x_{1} x_{2} x_{4}+\beta_{25} x_{1} x_{3} x_{4}+\beta_{26} x_{2} x_{3} x_{4}+\beta_{27} x_{1} x_{2} x_{3} x_{4}
\end{aligned}
$$

From this model the most important points are the main effect, 2-way interaction, 3-way interaction and 4-way interaction. So the fourth order model can be reduced as below:

$$
\begin{aligned}
& y^{\prime \prime \prime}=c+\beta_{1} x_{1}+\beta_{2} x_{2}+\beta_{3} x_{3}+\beta_{4} x_{4}+\beta_{6} x_{1} x_{2}+\beta_{7} x_{1} x_{3}+\beta_{8} x_{1} x_{4}+\beta_{9} x_{2} x_{3}+\beta_{10} x_{2} x_{4}+\beta_{11} x_{3} x_{4} \\
& +\beta_{12} x_{1} x_{2} x_{3}+\beta_{13} x_{1} x_{2} x_{4}+\beta_{14} x_{1} x_{3} x_{4}+\beta_{15} x_{2} x_{3} x_{4}+\beta_{16} x_{1} x_{2} x_{3} x_{4}
\end{aligned}
$$

This model parameters can be solved using least squares method. $\beta$ are the model parameters, $x_{1}=$ cutting speed, $x_{2}=$ feedrate, $x_{3}=$ axial depth and $x_{4}=$ radial depth. The fourth order model for torque and power are:

$$
\begin{aligned}
& T^{\prime \prime \prime}=-216-0.0625 x_{1}+512 x_{2}+30 x_{3}+63.5 x_{4}+5.5 x_{1} x_{2}+0.7031 x_{1} x_{3}-0.0625 x_{1} x_{4}+444 x_{2} x_{3} \\
& -155 x_{2} x_{4}-3.75 x_{3} x_{4}-10 x_{1} x_{2} x_{3}-1 x_{1} x_{2} x_{4}-0.2266 x_{1} x_{3} x_{4}-139 x_{2} x_{3} x_{4}+2.75 x_{1} x_{2} x_{3} x_{4} \\
& P^{\prime \prime \prime \prime}=-6272+18176 x_{2}+768 x_{3}+1856 x_{4}+144 x_{1} x_{2}+18 x_{1} x_{3}-4 x_{1} x_{4}+12672 x_{2} x_{3} \\
& -4608 x_{2} x_{4}-72 x_{3} x_{4}-272 x_{1} x_{2} x_{3}-20 x_{1} x_{2} x_{4}-5 x_{1} x_{3} x_{4}-4736 x_{2} x_{3} x_{4}+90 x_{1} x_{2} x_{3} x_{4}
\end{aligned}
$$

The variance analysis for the torque and power carried out to determine the model adequate and significant of 4-way interaction for both model are shown in table 6 and 7. From the variance analysis both model not significant to the 4-way interaction since the $\mathrm{p}$ value $>0.05$. The fourth-order model is adequate for torque and power since the $\mathrm{p}$-value for lack of fit for torque is 0.599 and for power is 0.123. F-static for torque and power are 0.99 and 7.53. 
Table 6: $\quad$ Variance analysis for fourth-order torque model.

\begin{tabular}{|c|c|c|c|}
\hline Source & Degree of freedom & F ratio & P-value \\
\hline Main effect & 4 & 6.38 & 0. \\
\hline 2-Way Interactions & 6 & 0.55 & 0.761 \\
\hline 3-Way Interactions & 4 & 0.16 & 0.956 \\
\hline 4-Way Interactions & 1 & 0 & 1 \\
\hline Residual error & 11 & & \\
\hline Lack of Fit & 9 & 0.99 & 0.599 \\
\hline Total & 26 & & \\
\hline
\end{tabular}

Table 7: $\quad$ Variance analysis for fourth-order power model.

\begin{tabular}{|c|c|c|c|}
\hline Source & Degree of freedom & F ratio & P-value \\
\hline Main effect & 4 & 20.22 & 0. \\
\hline 2-Way Interactions & 6 & 1.41 & 0.294 \\
\hline 3-Way Interactions & 4 & 0.97 & 0.463 \\
\hline 4-Way Interactions & 1 & 0 & 1 \\
\hline Residual error & 11 & & \\
\hline Lack of Fit & 9 & 7.53 & 0.123 \\
\hline Total & 26 & & \\
\hline
\end{tabular}

\section{Conclusion}

Reliable torque models have been developed and utilized to enhance the efficiency of the milling 618 stainless steel. The torque equation shows that feed rate, cutting speed, axial depth and radial depth play the major role in producing the torque. The higher the feed rate, axial depth and radial depth, the torque generated is very high compared with low value of feed rate, axial depth and radial depth. Contours of the torque outputs were constructed in planes containing two of the independent variables. These contours were further developed to select the proper combination of cutting speed, feed, axial depth and radial depth to produce the optimum torque. The higher the feed rate, cutting speed, axial depth and radial depth, the power generated is very high compared with low value of feed rate, cutting speed, axial depth and radial depth. Dual response contours of torque and power are very useful in assessing the maximum attainable torque. The third order model and fourth order model very important to investigate the 3-way interaction and 2-way interaction. The third order model and fourth order model shows that the 3-way interaction and 4-way interaction are not significant. 


\section{Acknowledgement}

The financial support of the University Tenaga Nasional is gratefully acknowledged.

\section{References}

[1] Montgomery, D.C., Design and Analysis of Experiments, 2nd ed., John Wiley, New York, 1984.

[2] El Baradie, M.A., Surface roughness model for turning grey cast iron (154BHN). Proc. of Institution of Mechanical Eng, Part B. Journal of Engineering Manufacture: pp. 43-54, 1993.

[3] Hasegawa, M., A. Seireg, R.A. Lindberg, Surface roughness model for turning. Tribology International, pp. 285-289, 1976

[4] Sundaram, R.M., Lambert, B.K., Mathematical models to predict surface finish in fine turning of steel. Part I, International Journal of Production Research, 19, pp. $547-556,1981$

[5] Mead, R., Pike, D.J., A review of response surface methodology from a biometric viewpoint. Biometrics, 31, pp. 803 - 851, 1975 Hill, W.J., Hunter, W.G., A review of response surface methodology: a literature survey. Technometrics, 8, pp. 571 - 590, 1966

[6] Hicks, C.R., Fundamental Concepts in the Design of Experiments, 4th ed., Saunders College Publishing, Holt, Rinehart, and Winston, 1993.

[7] Box, G.E.P., Draper, N.R., Empirical model-building and response surfaces, New York, John Wiley \& Sons, 1987

[8] Box, G.E.P., Behnken, D.W., Some new three level designs for the study of quantitative variables. Technometrics, 2, pp. 455-475, 1963

[9] Khuri, A.I., Cornell, J.A., Response Surfaces: Designs and Analyses. Marcel Dekker, Inc, 1987 